\title{
Crack Paths in Weld Details under Combined Normal and Shear Loading
}

\author{
Y. Sumi \\ Systems Design for Ocean-Space, Faculty of Engineering, \\ Yokohama National University \\ 79-5 Tokiwadai, Hodogaya-ku, Yokohama 240-8501, Japan, sumi@ynu.ac.jp
}

\begin{abstract}
In welded plate structures, fatigue cracks may initiate at the intersections between the flanges of longitudinal stiffeners and the web-stiffener attached to a transverse girder. The weld toe cracks may initiate and propagate in the flange of the longitudinal stiffener, while in certain cases they may initiate from the root of the fillet weld resulting in the separation of the web-stiffener from the flange. In order to investigate such a morphological change of crack growth behavior, series of fatigue tests have been carried out, and the morphological variation of these fatigue cracks are successfully identified in terms of the normal and shear stress distribution acting along the fillet weld between the flange and the attachment.
\end{abstract}

\section{INTRODUCTION}

In welded plate structures, fatigue cracks may initiate at the intersections between the flanges of longitudinal stiffeners and the web-stiffener attached to a transverse girder [1, 2]. The weld toe cracks may initiate and propagate in the flange of the longitudinal stiffener, while in certain cases they may initiate from the root of the fillet weld resulting in the separation of the web-stiffener from the flange. In order to investigate such a morphological change of crack growth behavior, series of fatigue tests have been carried out.

The applied stress and residual stress of the test specimens are equivalent to those attained in weld details of marine structures. Various attachments are welded on the flange of beam specimens, which are loaded by three-point bending conditions. The specimens are designed in such a way that in some cases, fatigue cracks initiate and propagate in the flange, while in other cases they may propagate along the fillet weld between the flange and the attachment. In the latter case, multiple fatigue cracks initiate from the root of the weld, showing rather complicated factory-roof shaped crack surfaces possibly due to the out-of-plane shear-mode loading.

In order to identify the governing parameters of the various cracking behavior, a series of finite element stress analyses are carried out by considering the effects of nonpenetrated weld using solid elements. It is found that the morphological variation of 
these fatigue cracks are successfully categorized in terms of the averaged normal and shear stress distribution acting along the fillet weld.

\section{MORPHOLOGY OF FATIGUE CRACKS AT THE INTERSECTION OF FLANGE AND ATTACHMENT}

In this section we shall discuss the two distinct type of fatigue cracking phenomena observed in our previous investigation [1].

\section{Separation of Web-Stiffener from a Flange}

Figure 1 is a schematic illustration of the fatigue test specimen, Sp2003. The material used is a structural steel SM490A specified in JIS standard. The specimens are designed so that the applied stress, residual stress, and structural redundancy are equivalent to those attained in ship structures. The specimens consist of three longitudinal stiffeners and a transverse girder at the middle span. The center longitudinal stiffener is connected to the transverse girder with a large bracket. A fatigue crack initiation is expected only at the intersection of the center longitudinal stiffener and the end of the web-stiffener. The loading condition is the three-point bending, and the applied hotspot stress range is set to $120 \mathrm{MPa}$ at the critical point.

The fatigue cracks exhibited the following behavior (see Fig.2);

(1) a fatigue crack initiates at the end of the bracket, and propagates into the faceplate,

(2) other cracks initiate from the weld root, and propagate to coalesce with the first crack,

(3) the first crack is arrested in the face-plate, and

(4) the secondary cracks propagate into the face-plate.

From the observed crack growth behavior, it is inferred that the cracks may repeat the above process (2)-(4), so that they may result in the separation of the web-stiffener from the face-plate.

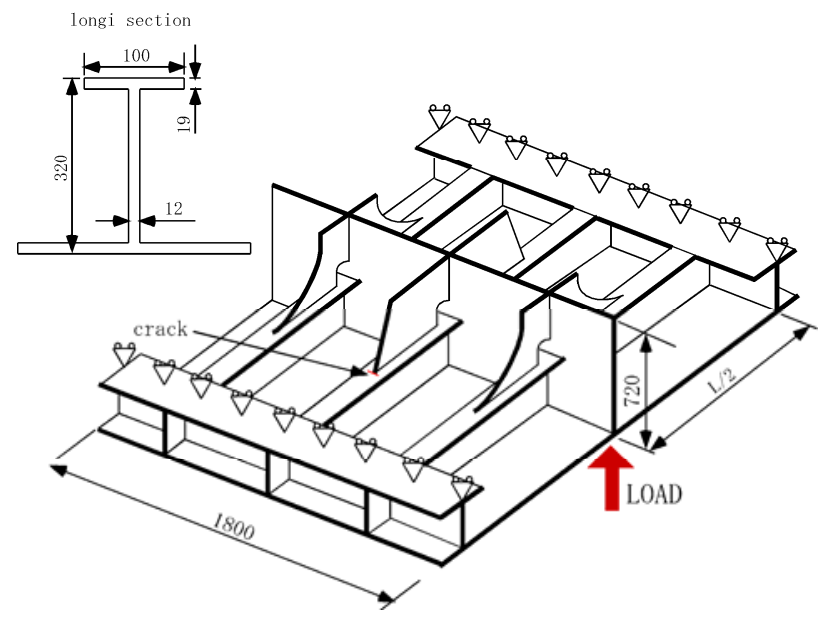

Figure 1. Fatigue test specimen, Sp2003. 


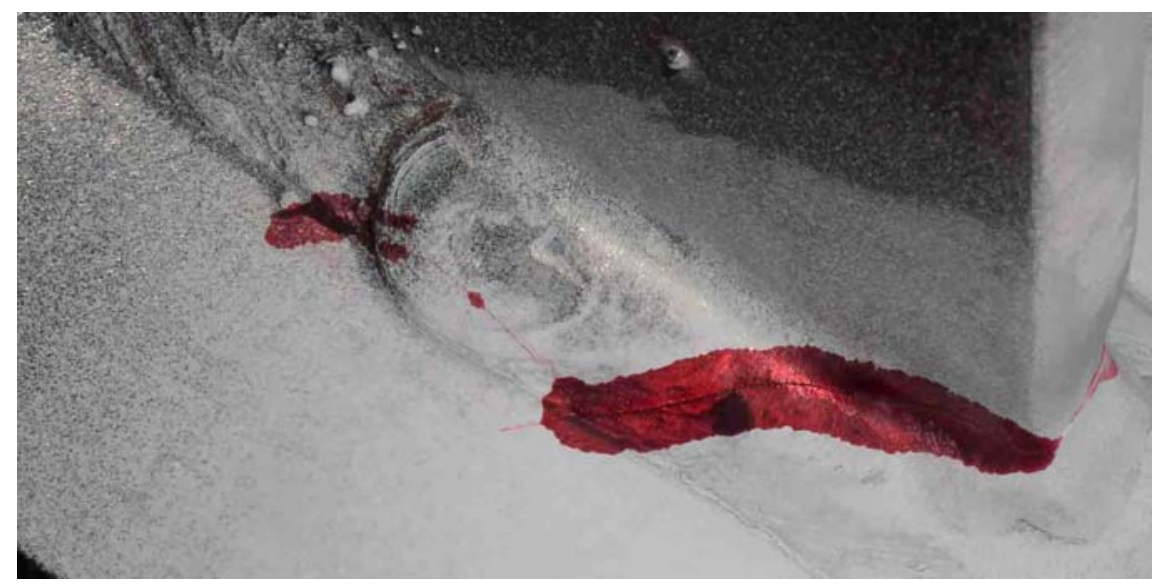

Figure 2. Crack propagation in test specimen, Sp2003.

Figure 3 shows the fracture surface of the specimen, where multiple fatigue cracks are initiated from the weld root, and their crack surfaces show slightly inclined angles due to the high out-of-plane shear stress with respect to the plane of the lack-of-penetration zone.

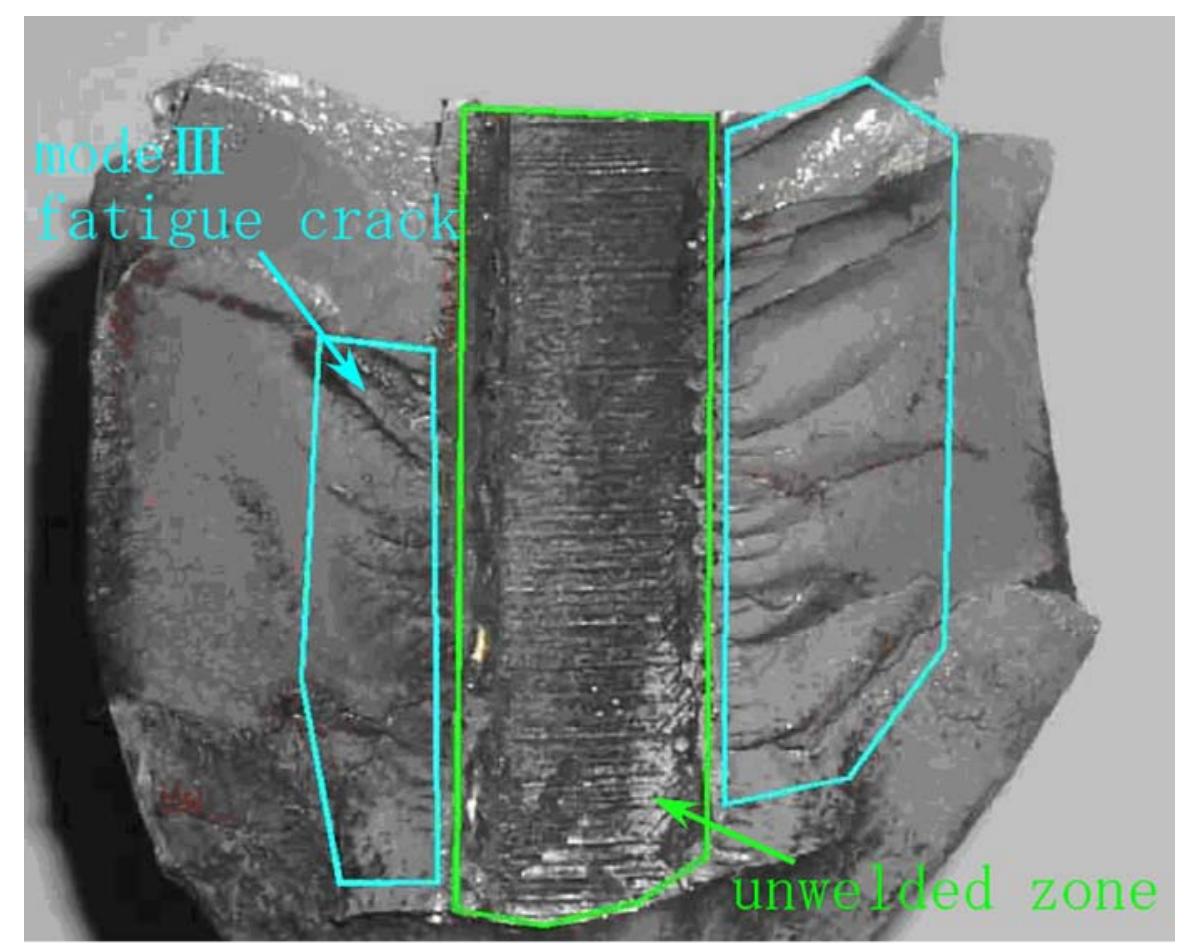

Figure 3. Fracture surface of test specimen, Sp2003. 


\section{Weld-Toe Cracks in a Flange}

Figure 4 is a schematic illustration of the fatigue test specimen, Sp2005, and the loading conditon, where a fatigue crack was initiated at the weld toe of the face-plate, and propagated in the flange (see Fig.5).

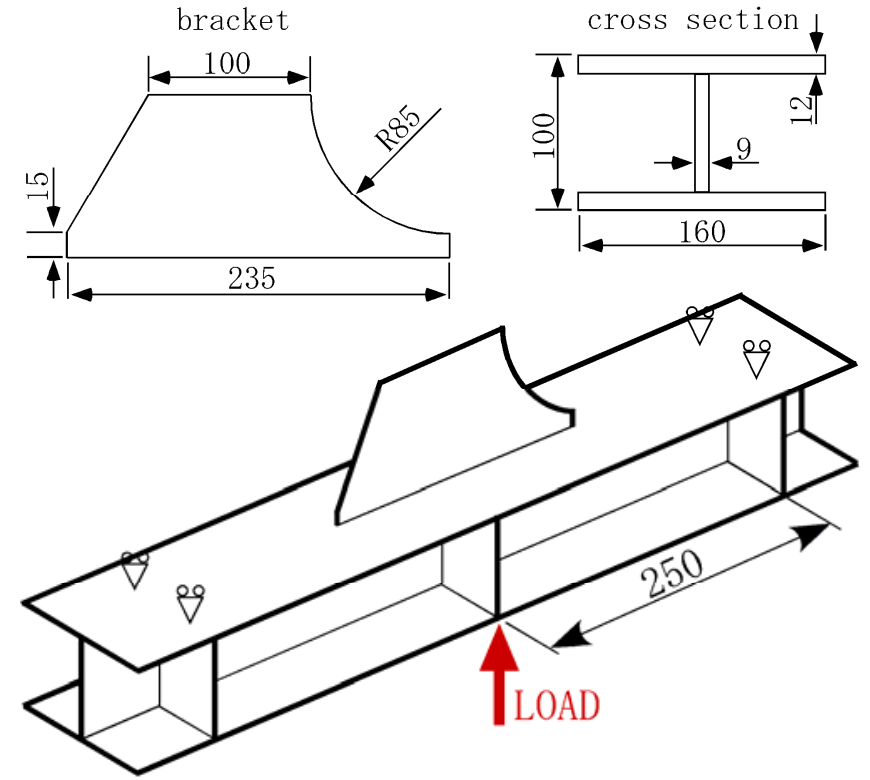

Figure 4. Fatigue test specimen, Sp2005.

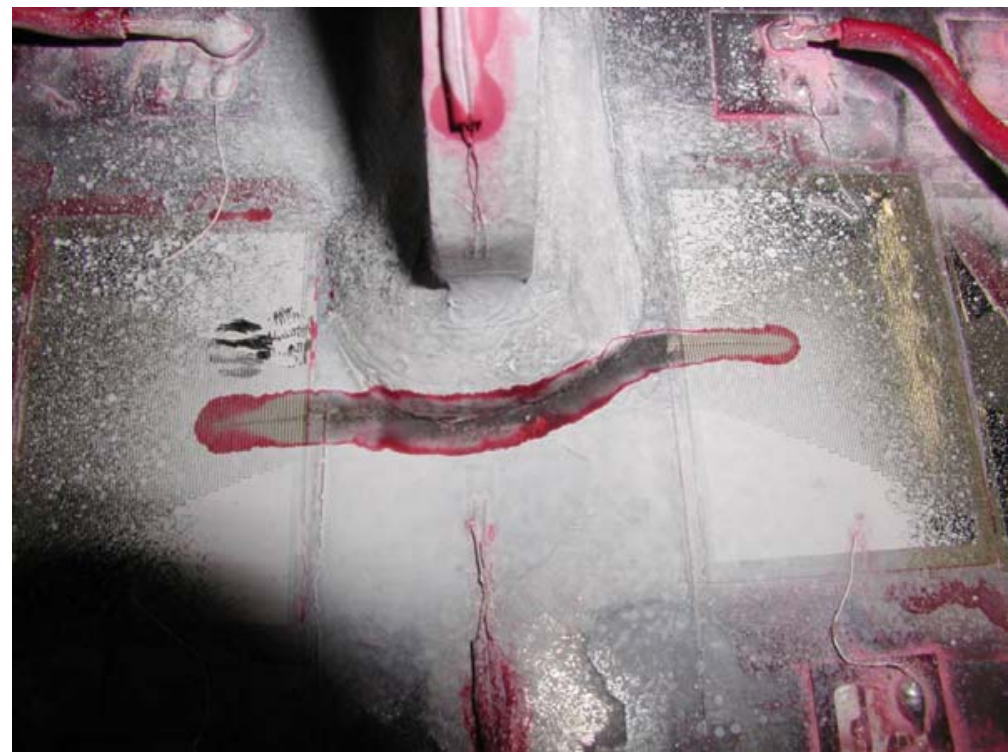

Figure 5. Weld-toe crack of test specimen, Sp2005. 


\section{TEST SPECIMENS DESIGNED BY STRESS ANALYSIS AND RELEVANT PARAMETERS FOR THE IDENTIFICATION OF CRACK MORPHOLOGY}

\section{Stress Analyses of Specimens, Sp2003 and Sp2005}

In order to identify the governing parameters of the two distinct cracking behavior oberved in Sp2003 and Sp2005, finite element stress analyses are carried out by considering the effects of non-penetrated weld using three-dimensional solid elements. The weld geometry is modelled as illustrated in Fig.6, where the non-penetrating zone of width, $t_{b}$, is discontineous in the finite element calculation.
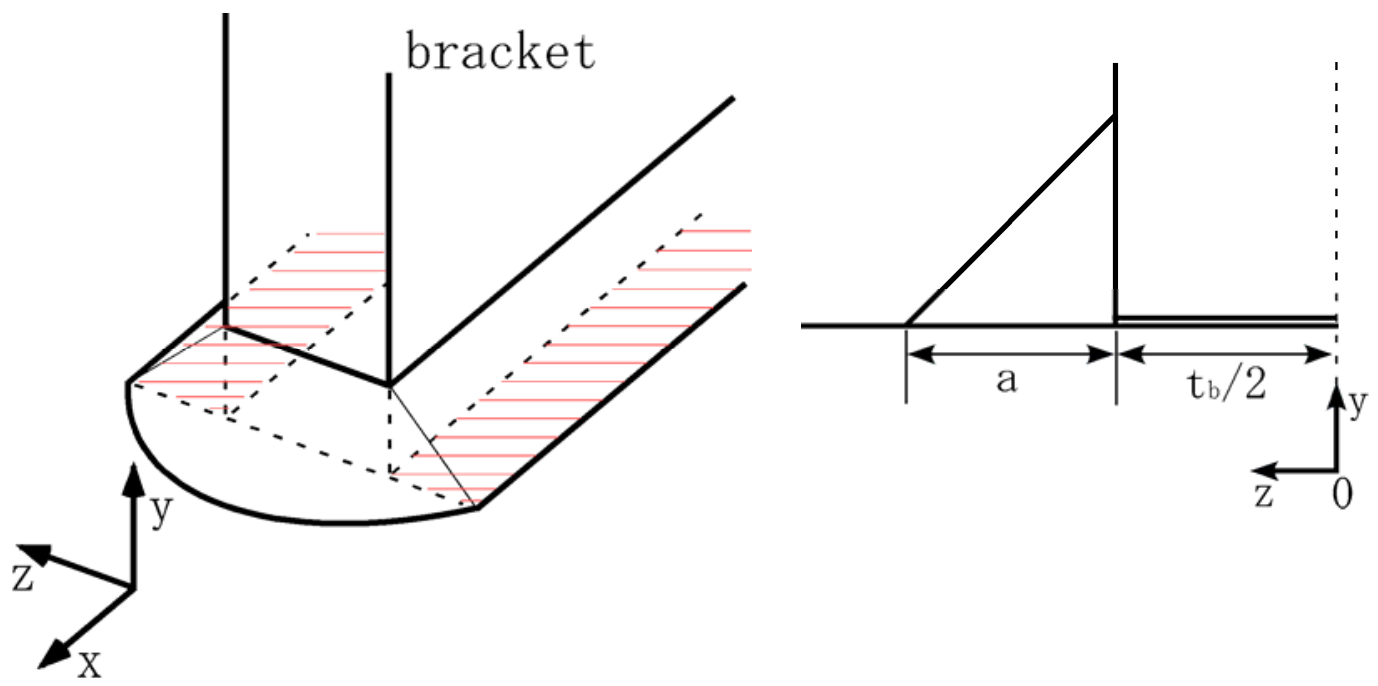

Figure 6. Modelling of weld toe (a:leg length, $\mathrm{t}_{\mathrm{b}}$ :width of non-penetrating weld).

In order to evaluate the local stess-effects to the crack morphology, averaged normal stresses and shear stress are introduced in the present paper. As expressed in the following equations, the longitudinal normal stress is averaged in the leg length of the weld and attachment thickness, while the shear stress and lateral normal stress are averaged in the fillet weld;

$$
\begin{gathered}
\bar{\sigma}_{x}=\frac{1}{a+t_{b} / 2} \int_{0}^{a+t_{b} / 2} \sigma_{x}(z) d z, \\
\bar{\sigma}_{y}=\frac{1}{a} \int_{t_{b} / 2}^{a+t_{b} / 2} \sigma_{y}(z) d z, \\
\bar{\tau}=\frac{1}{a} \int_{t_{b} / 2}^{a+t_{b} / 2} \tau(z) d z .
\end{gathered}
$$

The distribution of the averaged stresses are evaluated for the specimens, and the results are illustrated in Figs.7 and 8, where one can see the relatively higher shear stress is in Sp2003 in comparison with that in Sp2005. This is clearly indicated by the ratio of the 
shear stress to the longitudinal normal stress in Fig.9, and this difference may result in the completely different cracking pattern of these two specimens.

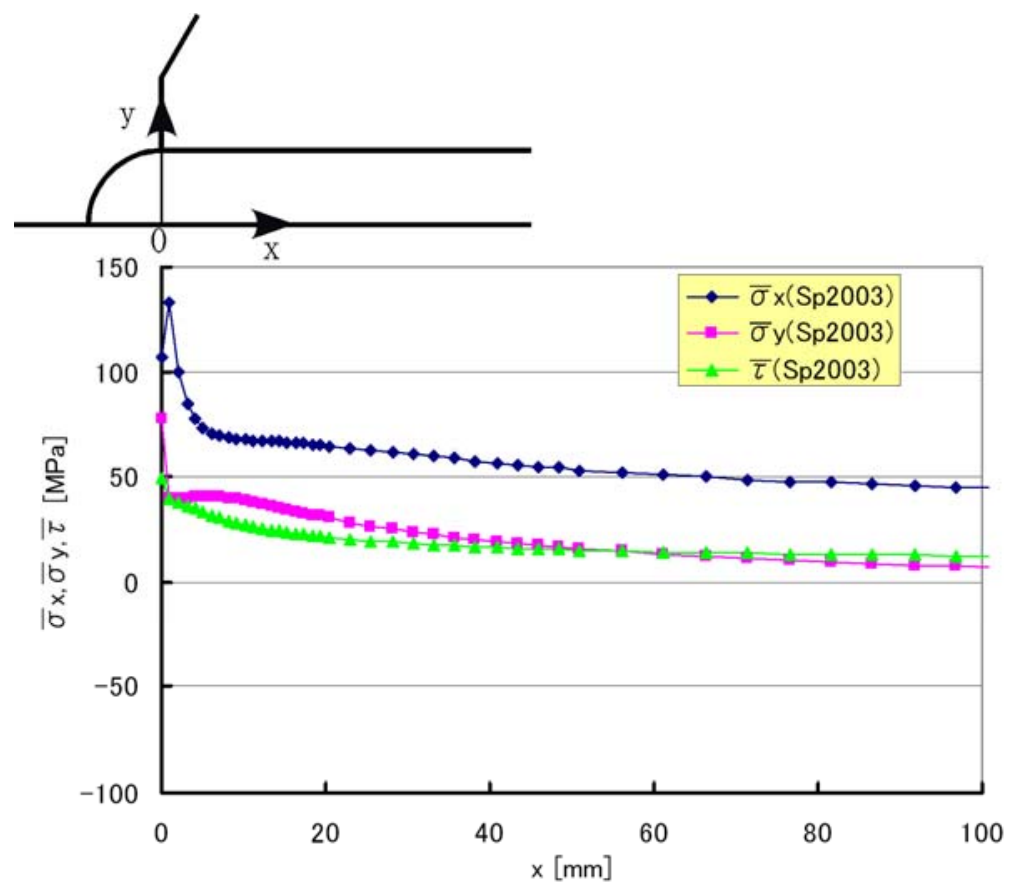

Figure 7. Averaged stress distribution of Sp2003.

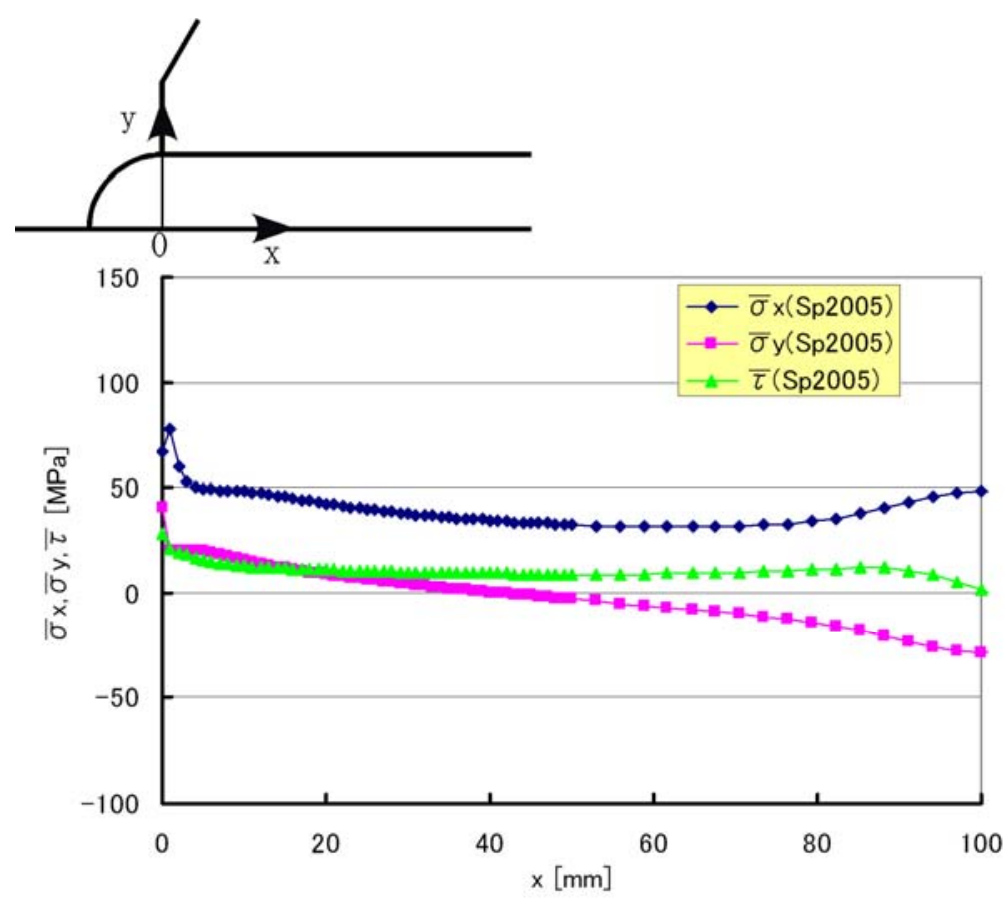

Figure 8. Averaged stress distribution of Sp2005. 


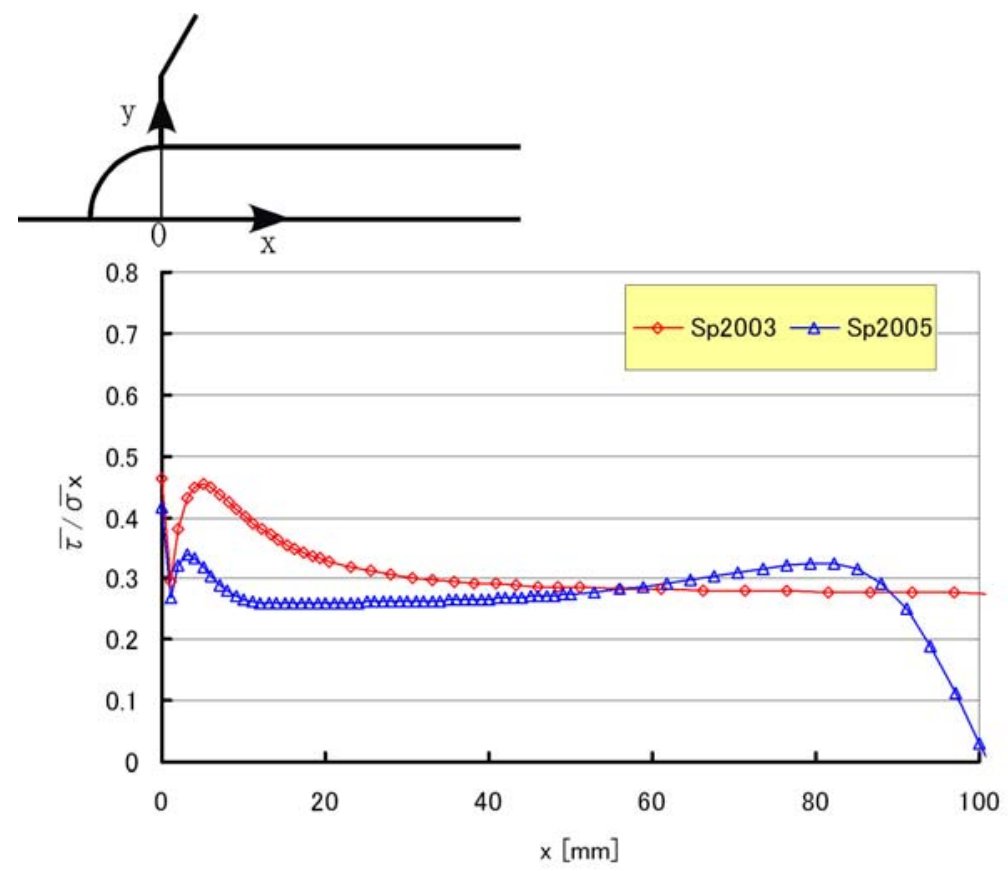

Figure 9. Averaged shear and normal stress ratio of Sp2003 and Sp2005.

\section{Design of Fatigue Test Specimens}

Based on the experimental and numerical results in the previous subsections, we have designed four test specimens in order to categorize the cracking patterns in terms of the stress parameters near the weld toe of the wrap-around weld connection. The basic geometry of the test specimen is illustrated in Fig.10, where the weld toe of the attachment on the upper flange is the possible crack initiation site.

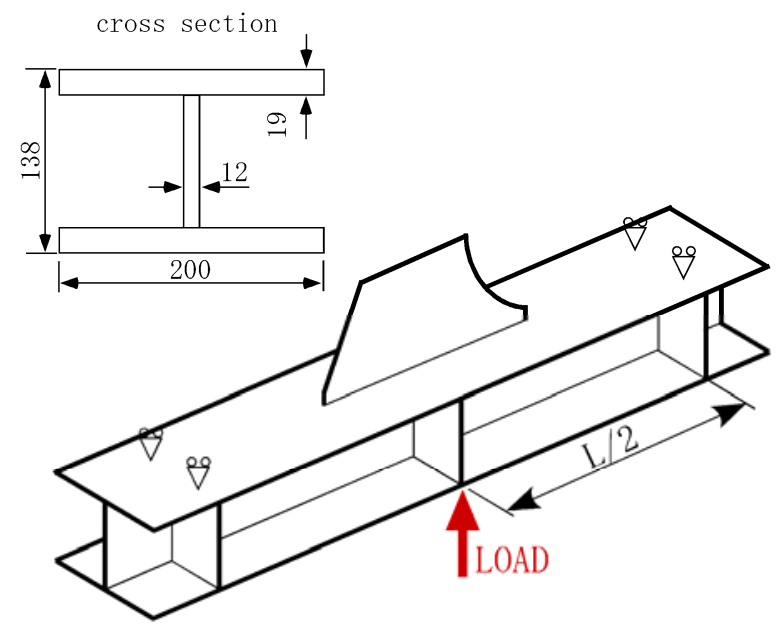

Figure 10. Common geometry of test specimens No.1-4. 
Mechanical properties and chemical composition of the steel are listed on Table1. The attached brackets of the specimens are designed differently as shown in Table 2 and Fig.11, so that the shear and normal stress levels are changed resulting in a variety of crack growth behavior. The loading conditions are listed on Table 3.

Table 1. Mechanical properties and chemical compositions.

\begin{tabular}{|c|c|c|c|c|c|c|}
\hline \multicolumn{7}{|c|}{ Mechanical Properties } \\
\hline \multicolumn{2}{|c|}{ Yield stress [MPa] } & \multicolumn{3}{|c|}{ Tensile strength $[\mathrm{MPa}]$} & \multicolumn{2}{|c|}{ Elongation [\%] } \\
\hline \multicolumn{2}{|c|}{381} & \multicolumn{3}{|c|}{521} & \multicolumn{2}{|c|}{25} \\
\hline \multicolumn{7}{|c|}{ Chemical composition [\%] } \\
\hline $\mathrm{C}$ & $\mathrm{Si}$ & $\mathrm{Mn}$ & $\mathrm{P}$ & $\mathrm{S}$ & $\mathrm{Nb}$ & V \\
\hline 0.13 & 0.25 & 1.25 & 0.013 & 0.004 & 0.012 & 0.002 \\
\hline
\end{tabular}

Table 2. Test specimens

\begin{tabular}{|c|c|c|c|c|}
\hline \multirow{2}{*}{$\begin{array}{c}\text { Specimen } \\
\text { No. }\end{array}$} & \multirow{2}{*}{ Span } & \multirow{2}{*}{$\begin{array}{c}\text { Bracket } \\
\text { height }\end{array}$} & \multicolumn{2}{|c|}{ Stress level in weld } \\
\cline { 4 - 5 } & & $\tau$ & $\sigma_{\mathrm{y}}$ \\
\hline No1 & $800 \mathrm{~mm}$ & $200 \mathrm{~mm}$ & high & high \\
\hline No2 & $800 \mathrm{~mm}$ & $300 \mathrm{~mm}$ & high & high \\
\hline No3 & $800 \mathrm{~mm}$ & $90 \mathrm{~mm}$ & high & low \\
\hline No4 & $1,000 \mathrm{~mm}$ & $70 \mathrm{~mm}$ & middle & low \\
\hline
\end{tabular}

No. 1

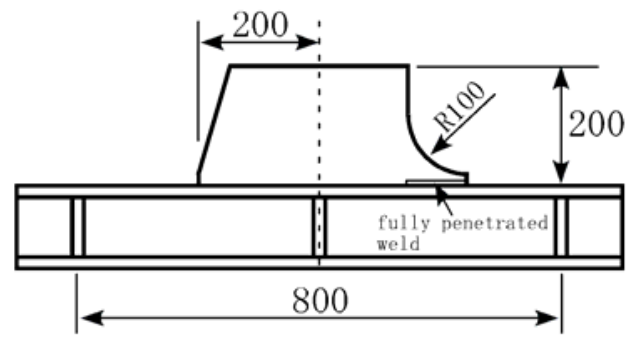

$\underline{\text { No. } 3}$

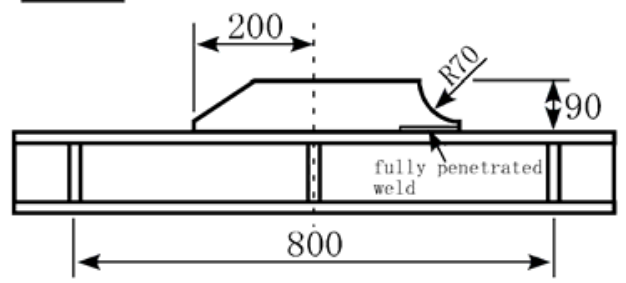

No. 2

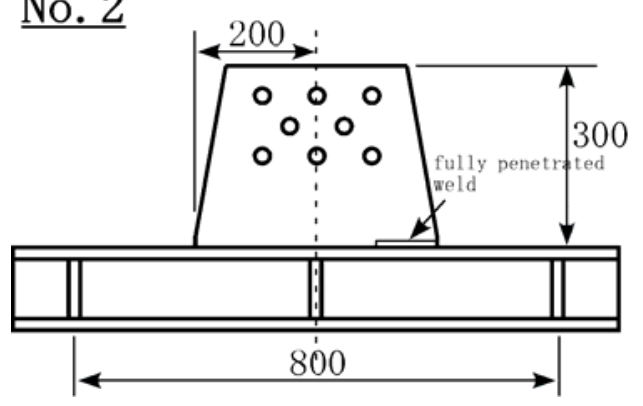

No. 4

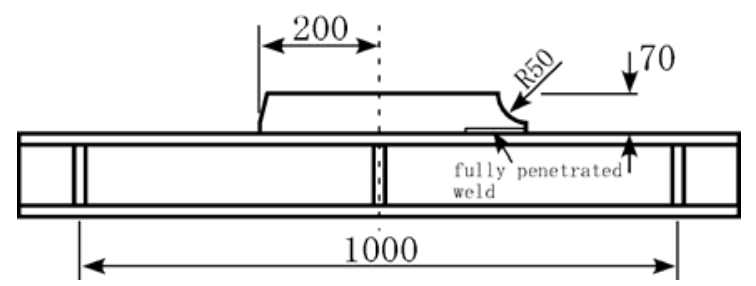

Figure 11. Geometry of test specimens No.1-4. 
Table 3. Loading conditions.

\begin{tabular}{|c|c|c|c|c|}
\hline Specimen No. & No1 & No2 & No3 & No4 \\
\hline$\Delta \sigma_{\text {hs }}$ & $200 \mathrm{MPa}$ & $100 \mathrm{MPa}$ & $200 \mathrm{MPa}$ & $200 \mathrm{MPa}$ \\
\hline Max. load & $372 \mathrm{kN}$ & $186 \mathrm{kN}$ & $430 \mathrm{kN}$ & $314 \mathrm{kN}$ \\
\hline Min. load & $19 \mathrm{kN}$ & $9 \mathrm{kN}$ & $22 \mathrm{kN}$ & $16 \mathrm{kN}$ \\
\hline
\end{tabular}

As illstrated in Fig.12, all specimens No. 1-4 have relatively high shear stress near the weld toe so that they may exhibit the failure mode to bracket separation, among which specimen No.4 has relatively low shear stress along the fillet weld.
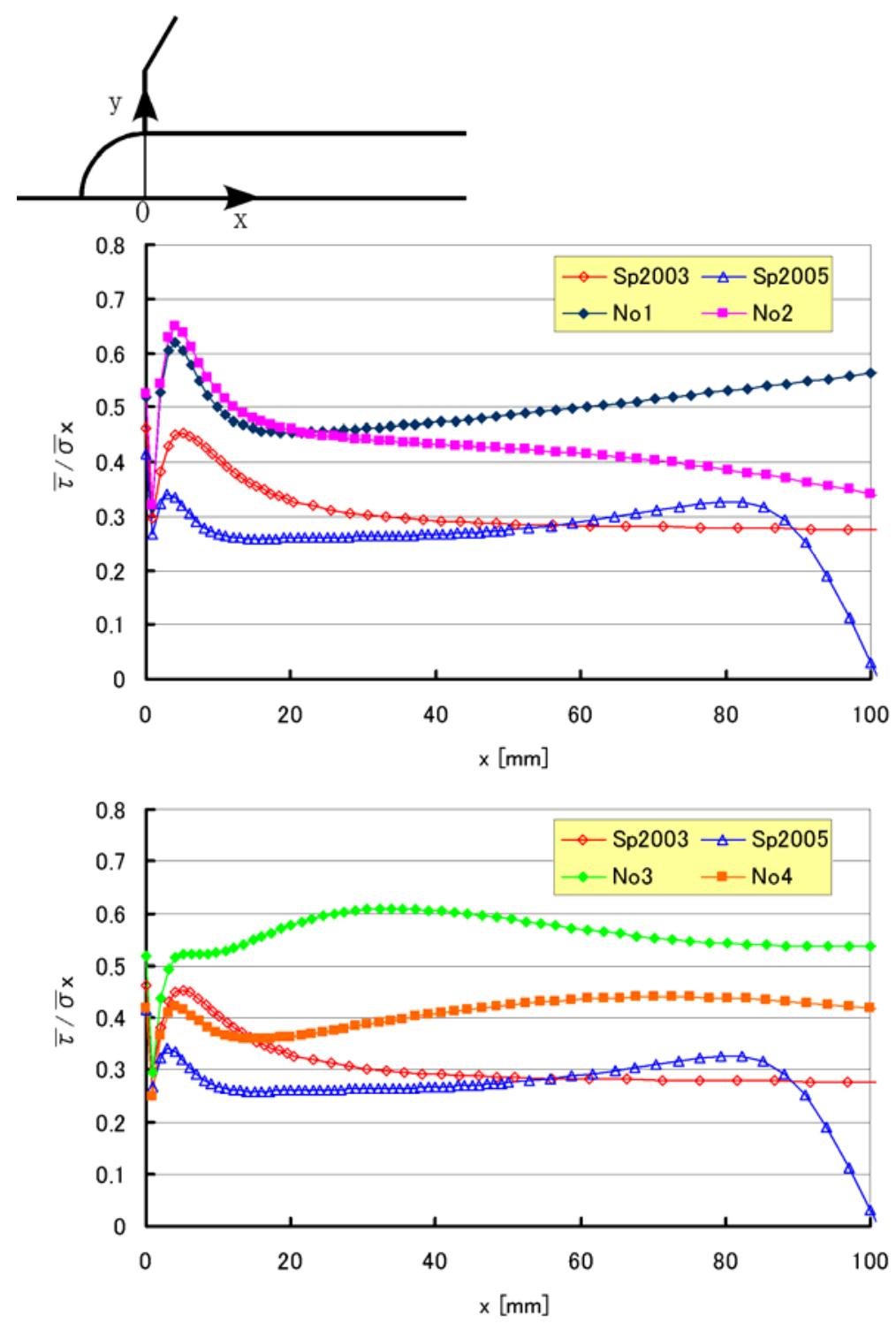

Figure 12. Averaged shear to normal stress ratio of specimens. 


\section{TEST RESULTS AND DISCUSSIONS}

\section{Crack Morphology of the Specimens}

The four specimens are tested, and the crack morphology is investigated by observing the specimen surface during the tests and also by examining the fracture surface after the tests. Specimens No.1-3 exhibit the bracket separation mode of failure (see Fig. 13), while the mixed flange and bracket separation failures are observed in Specimen No. 4 (see Fig. 14).

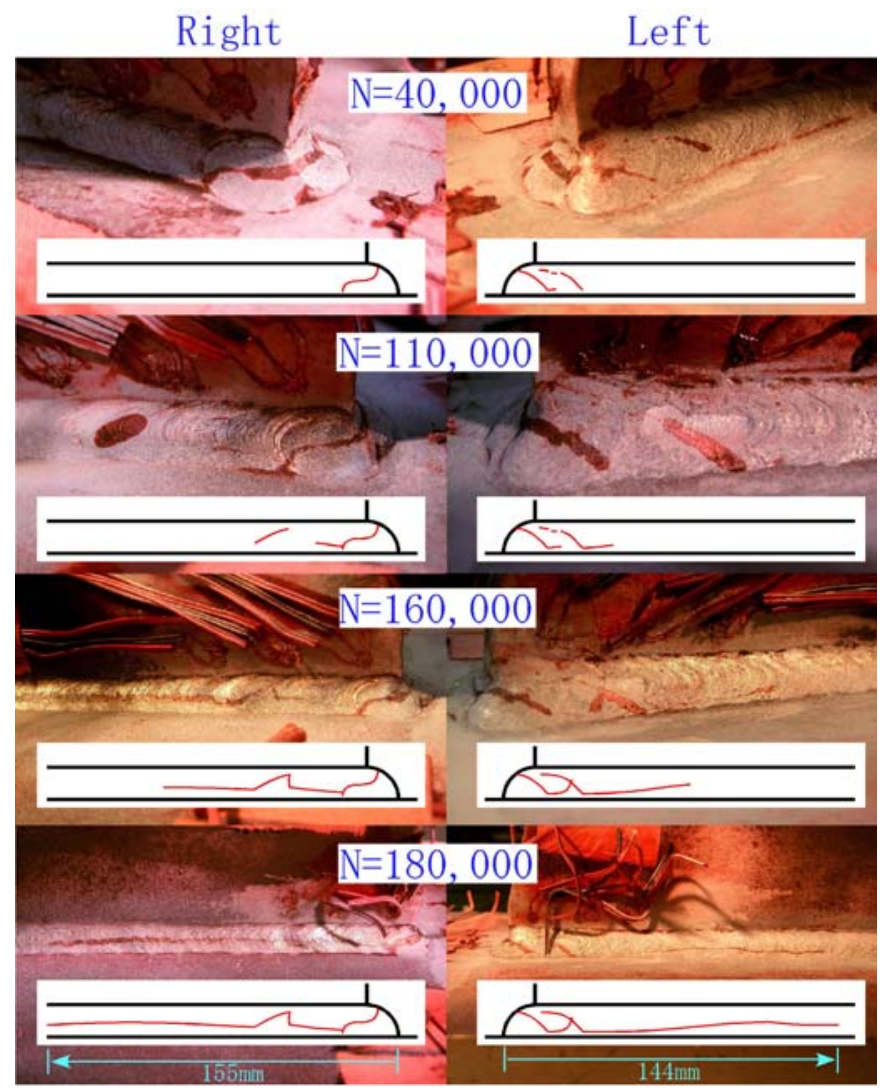

Figure 13. Bracket sparation mode of failure in Specimen No.1.

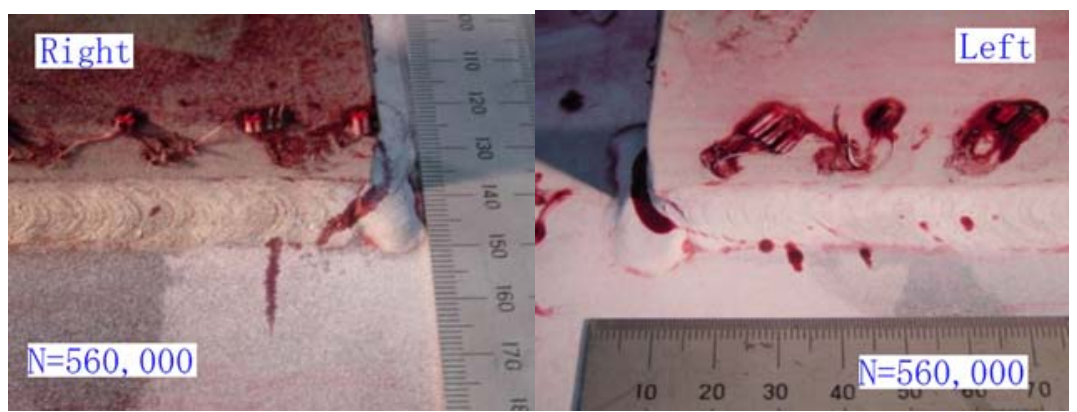

Figure 14. Mixed flange and bracket separation failures in Specimen No.4. 


\section{Discussions}

The morphology of the fatigue failure may generally be categorized into the following four modes; i.e.

(1) the initiation of a fatigue crack at the weld toe of the wrap-around weld, followed by the propagation in the flange resulting in the flange failure (Sp2005),

(2) the initiation of a fatigue crack at the upper end of the wrap-around weld, followed by the propagation through the weld metal resulting in the flange failure (Specimen No.4),

(3) the initiation of multiple fatigue cracks from the non-penetrated zone exhibiting the mode III failure along the fillet weld, resulting in the separation of the bracket (Sp2003, Specimens No.1-3), and

(4) the initiation of a fatigue crack at the upper end of the wrap-around weld, followed by the propagation along the fillet weld.

Based on the series of finite element stress analyses carried out for the fatigue test specimens, we propose the two parameters; i.e. the ratio of the averaged shear stress and longitudinal stresses, and the bi-axial stress ratio of the lateral and longitudinal normal stresses, which are schematically illustrated in the upper part of Fig.15. The lower part of the figure is the possible mapping of the crack morphology in terms of these parameteres. Naturally we can expect the failure mode (1) in the lower left zone due to the small effect of shear, while the failure mode (3) may occur in the upper right zone. The relatively high lateral stress may lead to the failure mode (4). The relatively high shear stress may intiate mode III cracks in the weld, but the longitudinal normal stress may lead the crack into the flange identified as the failure mode (2).

All the results of eight test specimens (Sp2003, Sp2005-1, Sp2005-2, Sp2005-3, and No.1-4) are plotted in Fig.15, so that we may draw the approxiamate boundaries of the for failure modes in this mapping chart.

\section{CONCLUSIONS}

A series of finite element stress analyses and fatigue tests are carried out in order to identify the governing parameters of the various cracking morphology at and near the wrap-around weld. It may be possible for the morphological variation of these fatigue cracks to be categorized into the four modes in terms of the averaged normal and shear stress distribution acting along the fillet weld, which include the mode III cracking from the non-penetrating zone of the weld.

\section{ACKNOWLEDGMENTS}

The authors express their sincere gratitude to Mr. M. Nakamura and Mr. M. Mohri, for their assistance on the experiments and numerical calculations. This work has been in parts supported by a training program of core human-resouces for industry from the 
Ministry of Economy, Trade and Industry, by Grant-in-Aid for Scientific Research (No.17206086) from the Ministry of Education, Culture, Sports, Science and Technology, and by Kawasaki Shipbuilding Co. to Yokohama National University. The author is grateful for their support.

\section{REFERENCES}

1. Okawa, T. Sumi, Y., Mohri, M. (2006). Marine Structures, 19: 217-240.

2. Doerk O, Fricke W. (2004). Fatigue strength assessment of fillet-welded toes of brackets and stiffeners. 9th Symposium on Practical Design of Ships and Other Floating Structures, Lubeck-Travemuende, Germany, 441-448.

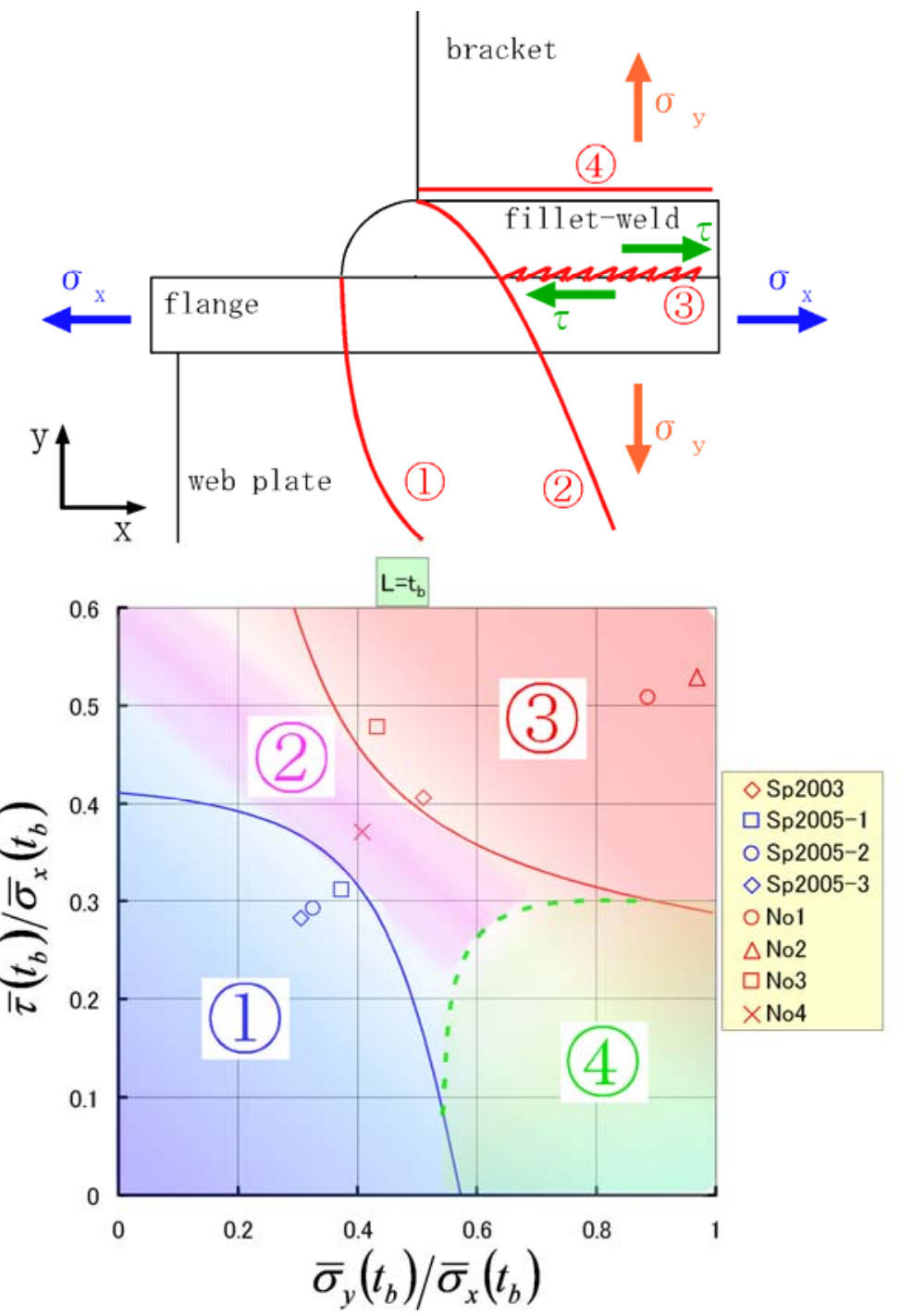

Figure 15. Identification of failure modes near the wrap-around weld. 